\title{
Early Childhood Education, Child Development and School Readiness: Evidence from Zambia
}

\begin{abstract}
While early childhood education has received increasing attention in the developing world in recent years, relatively little evidence is available from sub-Saharan Africa on its effects on child development and subsequent school enrolment. We use a prospective case-control design to evaluate the developmental impact of a community-based early childhood center in an urban area in Zambia. Comparing 40 children attending the center to 40 children not attending the center from the same community, we find that center attendance was associated with significantly better performance in an assessment of task orientation, and was also weakly associated with increased letter familiarity. We also observed higher performance among center students on tests of receptive language and pencil-related fine motor skills. These associations were, however, smaller and not statistically significant. We conducted a follow-up one year after the initial assessment, when children were seven years old and should have been in first grade. At follow-up, $27 \%$ of non-attendees were not yet enrolled in primary school, compared to just $11 \%$ of center students, suggesting that participation in early education encourages a timely transition into first grade.
\end{abstract}

Keywords: Early childhood care, school readiness, assessment tools

Stephanie Simmons Zuilkowski, Harvard Graduate School of education. E-mail: sls418@ mail.harvard.edu. Günther Fink, Department of Global Health and Population, Harvard School of Public Health. E-mail: gfink@hsph.harvard.edu. Corrina Moucheraud, Department of Global Health and Population, Harvard School of Public Health. E-mail: cmoucher@hsph.harvard.edu. Beatrice Matafwali, University of Zambia. E-mail: BMatafwali200o@yahoo.com 


\section{Introduction}

In the developed world, an extensive body of longitudinal research demonstrates the importance of children's early developmental experiences for educational and broader life outcomes (Abbott-Shim, Lambert, \& McCarty, 2003; Barnett, 1996; Barnett \& Masse, 2007; Camilli, Vargas, Ryan, \& Barnett, 2010; Gorey, 2001; Ludwig \& Miller, 2007; Puma et al., 2005; Reynolds, 2000; Schweinhart et al., 2005). To date, relatively little evidence is available on the developmental effects of early childhood education (ECE) programs on children in sub-Saharan Africa. Though the evidence supporting early childhood education in developed countries is strong, it cannot be assumed that this evidence translates directly to the context of sub-Saharan African countries. However, several recent studies conducted in Kenya, Zanzibar and Uganda (Malmberg, Mwaura, \& Sylva, 2011; Mwaura, Sylva, \& Malmberg, 2008); Botswana (Taiwo \& Tyolo, 2002); South Africa (Liddell \& Rae, 2001); and Guinea and Cape Verde (Jaramillo \& Tietjen, 2001) support the argument that ECE is just as important in preparing African children for later academic success as it is for those living in the developed world.

Despite this emerging evidence, government investment in early childhood education remains low in the region. With the international focus on the basic primary schooling targets set out in the Millennium Development Goals', the resources available to ECE are generally limited, and have in some cases even been reallocated towards primary schooling. In Kenya, for example, pressures to enrol more children in overcrowded primary schools led to the closing of some preschool programs that had been located in those schools (Nganga, 2009). Some have suggested that in Zambia, attempts to expand ECE "may be premature and potentially damaging to an already tenuous education system" (Thomas \& Thomas, 2009, p.6). In addition, the inter-sectoral nature of ECE programs-generally involving, at a minimum, ministries of health and education-provides an additional challenge to implementation (Pence et al., 2004).

The lack of government support for early childhood education means that these programs are likely to be costly to parents or, if affordable, of low quality. As a consequence, ECE net enrolment rates are in the single digits for many countries in the region, including Burkina Faso, Senegal, Eritrea, and Ethiopia (UNESCO, 2011). Quality is undeniably critical in ECE, both in attracting parents to enrol their children and in producing positive developmental outcomes. Rao and colleagues (2010) found that disadvantaged children in India who attended higher-quality preschool programs experienced greater developmental growth than those attending poorquality programs. However, the India study as well as recent evidence from Cambodia suggest that any early childhood education experience is beneficial to children (Rao, 2010; Rao et al., 2012). Therefore, we argue that Zambia and similar countries should

1 Millennium Development Goal 2a asks countries to “...ensure that, by 2015, children everywhere, boys and girls alike, will be able to complete a full course of primary schooling." (http://www.un.org/millenniumgoals/ education.shtml) 
begin building ECE systems, even if these programs cannot initially meet international definitions of high quality.

Zambia is in many respects representative of a larger group of countries in the region-struggling to balance pressing demands to improve health and education in a context of limited resources. Despite significant progress made in recent years, the Republic of Zambia remains among the poorest countries in the world. Zambia's current population is estimated at 13 million people, and average per capita annual income was estimated at US \$1,400 in 2010 (World Bank, 2012). With an under-5 mortality rate of 111 per 1000 and an HIV prevalence rate of over 13.5\% among individuals aged 15-49, life expectancy at birth remains below 50 years (Unicef, 2012; World Bank, 2012).

High fertility rates and a rapidly growing youth population continue to pose major challenges for governmental education planners and practitioners. Aided by the removal of attendance and examination fees in 2002, school enrolment at lower grades is now near-universal and gross enrolment ratios frequently exceed $100 \%$ at the basic school level (Kemp, Elbers, \& Gunning, 2008). However, many students enter primary school at age 8 or later, and dropout rates remain high, with less than $50 \%$ of students progressing to secondary schooling (Macro International, 2007). With severely constrained overall educational resources, the Zambian public ECE sector has remained largely underdeveloped: it lacks a national curriculum and policy framework, and suffers from a shortage of qualified teachers. There is also low coordination among key stakeholders to facilitate holistic implementation of early childhood programs (Matafwali, 2007). Overall, Zambian children's exposure to early childhood programs appears limited. Only $17 \%$ of new first-graders reported any early childhood care and education experience in 2010 (UNESCO, 2010), while the projection for the year 2015 stands at 30\% (Republic of Zambia Ministry of Education, 2010).

This paper generates a first assessment of the degree to which ECE can lead to better educational outcomes in the Zambian context. The specific program we examine is the Amundame center, located in Zambia's Central Province. Started in 2004 with initial support from the Maureen Mwanawasa Community Initiative, Amundame (a name derived from the local language Lenje, literally interpreted as "Take Care of Me") is among the most well-known early childhood centers in Zambia. The center is operated as a community-based initiative for children of women working as vendors in the market of Kapiri Mposhi, a small urban center. The center's curriculum focuses on pre-literacy and early numeracy skills, and includes a school feeding component.

The main hypothesis we investigate in this paper is that early childhood education and care provided by the center will lead to improved cognitive and physical development, and consequently result in improved readiness for primary school. We further hypothesize that improved school readiness will lead to earlier enrolment in primary school, and improve children's long term educational outcomes. 


\section{Methods}

\section{Ethical review}

The study was approved by the University of Zambia Humanities and Social Sciences Research Ethics Committee and the Institutional Review Board at the Harvard School of Public Health.

\section{Study setting}

This center was selected for study based on the recommendations of Zambian academics and local nongovernmental organization representatives, some of whom had observed the center's operations extensively. According to a recent study, the center met or exceeded the minimum standards expected of a quality ECE program in four categories: curriculum, trained teachers, nutrition, and availability of teaching and learning materials (Matafwali \& Munsaka, 2011). The center is located in Kapiri Mposhi, a medium-sized urban center in Zambia's Central Province, approximately one hundred miles north of the country's capital, Lusaka (see Figure 1). The Amundame center is situated within the town's market and accommodates children aged three to six, with a capacity of approximately forty children of each of these age groups (birth cohorts).The children are divided into two groups by age.

The center's mission is to prevent children from spending key developmental years unattended in the market and to expose these children to early learning, thereby improving their school readiness. The center is open year-round, five days per week. The three classrooms contain a variety of toys, books, and learning tools. Some of these objects are handmade from local materials, while others have been purchased by UNICEF and other donors. The walls are covered with letters, numbers, maps, and art created by the staff. The center has a walled-in outdoor play area used for games, free play time, and meals. Initially, the school feeding program served children two hot meals per day (breakfast and lunch). Financial constraints have reduced the scope of this program; now at minimum one hot meal is served during the day, typically consisting of nshima (a thick maize porridge) with vegetables.

There is no mandatory standard curriculum framework for early childhood in Zambia. Therefore, most of the community-based ECE centers do not have any curriculum guidelines in place and this constrains the quality of services provided. However, the Amundame center follows the curriculum guideline from the Zambia Pre-school Association, a board that coordinates privately-owned and communitybased pre-schools in Zambia. The curriculum covers a broad range of skill areas such as language and literacy development, social studies, health, pre-mathematics, science, expressive arts, physical education, and art and design. The curriculum is mainly teacher-directed in areas such as literacy development and pre-math skills, whereas learning in science, expressive arts and design are learner-directed through exploration and creativity. 
Literacy development at the Amundame center mainly focuses on alphabetic knowledge with particular emphasis on letters and letter-sound relationships. Children are exposed to various activities aimed at enhancing early literacy skills, including print awareness. The projected outcome at preschool level is that children should demonstrate understanding and knowledge that letters make up words, that letters relate to sounds in spoken words and that words make up sentences. The teaching places emphasis on the phonic structures. Other distinct features of the program include the learner-centered approach in which children are paired in small groups to work on activities. Language development is enhanced through nursery rhymes and story-telling. Children are also encouraged to name common items at home and within the immediate environment. Regarding pre-mathematics skills, the areas of curricular focus include sorting and classifying objects, building with blocks, and comparing objects according to size, shape and colour. The teaching materials that are used to stimulate math skills are locally-made containers of different shapes and sizes, sand, stones, tires, and sticks, in addition to store-bought materials.

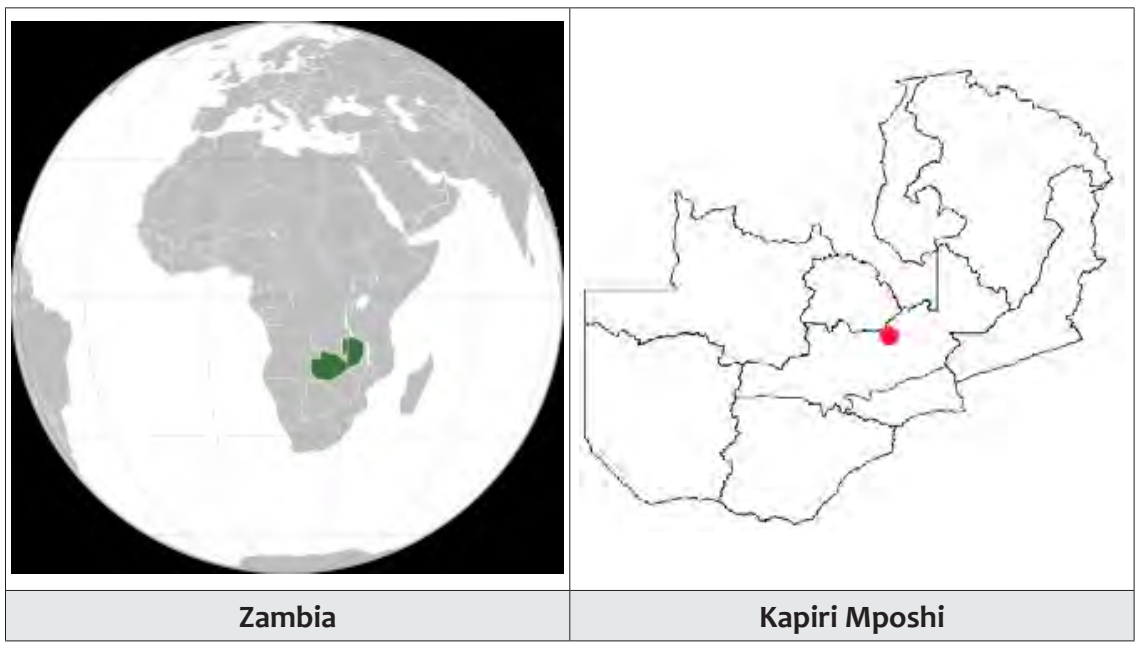

Figure 1: Study Location: Zambia and Kapiri M'poshi

In addition to a small number of paid staff, volunteers from the community (including parents and guardians of enrolled children) work at the center. The volunteers complete a basic training program run by the center's director and support the program in a number of ways, including preparing meals and cleaning. The volunteers do not have classroom responsibilities. Some have argued that relying on volunteers makes for unstable and uneven ECE programs, and places a low value on the important contribution of early child care workers (Young, 1996). However, this model makes the program affordable in a low-resource setting; at Amundame, parents pay only a minimal contribution towards teacher remuneration and the supply of materials such as toilet tissue and soap for hygiene purposes. Additionally, it should be noted that Amundame volunteers generally assist only a few days a month, working their 
schedule around other work and family commitments. Family participation may indeed be one of the mechanisms responsible for the results shown in the next section; research with low-income pre-schoolers in the United States suggests that parental volunteerism in children's schools is associated with better behavioural and academic outcomes (Marcon, 1999).

\section{Design and participant recruitment}

The study used a prospective case-control design. Given our objective-to measure the impact of the center on school readiness and on primary school enrolment-we focused on the oldest Amundame age group, who were born in 2004. Official school start age in Zambia is 7; with the school year starting in January, this implies that all children born in 2004 should have entered school by January $2012^{2}$. Given local popularity of the center and its limited capacity, enrolment is restricted to 160 children in total. Local community leaders decide which children are admitted to the center. The center allows only one child per family to attend, and tries to prioritize poor or otherwise vulnerable children. Using the center's administrative records, 40 children born in 2004 and attending the center for at least one year were identified, and, upon their assent and their parents' consent, enrolled in the study. In order to obtain a maximally comparable control group, we recruited an additional 40 children born in 2004 who never attended the center. Since center attendance is restricted to children of mothers working on the local market, we restricted recruitment to the market area in order to minimize the socioeconomic differences between children in the treatment and control groups. In practice this means that the control group children may have applied to the center and not been selected, or they may never have applied. According to their parents, several control group children had attended other ECE programs. However, given the generally low family incomes and the dearth of formal centers in the area, it is unlikely that such programs were of comparable quality to the Amundame center.

The small number of eligible treatment group children limits the statistical power for the study. In order to achieve power 0.8 , a minimum effect size of 0.63 standard deviations was required to achieve significance at the $\alpha=0.05$ level.

\section{Measures and testing procedure}

When research staff identified an eligible child, parents or guardians were given a brief explanation of the research study, given an opportunity to ask questions, and invited to participate in the study. If parents expressed willingness to participate, an interview was scheduled at the child's home. During the interview visit, parents and children were provided with further information on the scope and content of the study, and, upon their consent, were formally enrolled in the study. All assessments

2 Early enrollment in school is common in Zambia, with about $25 \%$ of children starting school at age six or earlier (Fink et al., 2012). 
were conducted in Bemba, the primary language in this region, by trained University of Zambia graduate students. The full battery of child development assessments lasted 60-75 minutes on average, and was followed by a parent survey collecting information on early childhood health and schooling experiences as well as household characteristics. Children were assessed using a combination of internationally- and locally-developed child development tests compiled for the Zambia Early Childhood Development Project as discussed in further detail in Fink et al. (2012).

Since the primary objective of the center is to improve school preparedness, we focus in this paper on four developmental measures related to school readiness: the Peabody Picture Vocabulary Test-Revised (PPVT-R), letter naming, a fine motor assessment focused on pencil skills, and task orientation.

The PPVT-R (Dunn \& Dunn, 1981) is an assessment of receptive language and is frequently used as a measure of school readiness (Bracken \& Fischel, 2007; Brown, Scott-Little, Amwake, \& Wynn, 2007; Geoffroy et al., 2010; Jeon et al.; PatrianakosHoobler, Msall, Marks, Dezheng, \& Schreiber, 2009; Romano, Babchishin, Pagani, \& Kohen). As described in Author el al (2012), the PPVT-R was adapted to the Zambian context by dropping culturally unsuitable items, and was translated into the local language. As a critical pre-literacy skill, letter naming is often used as an indicator of school readiness (Hanson et al., 2011; Prior, Bavin, \& Ong, 2011). In this task, children were shown a sheet with 24 upper- and lower-case characters, and asked to name the letters aloud. Pencil skills are less commonly tested as a school readiness measure in developed countries, where children often use crayons and other writing implements from an early age. But in the Zambian context, many children are not introduced to writing implements until first grade--so early exposure to writing tools may be of major advantage and thus increase school readiness. As part of this pencil skill task set, children were asked to copy a set of numbers, letters, and shapes, and assessors evaluated the accuracy of these reproductions as well as the child's grip on the pencil. The last school readiness characteristic analysed is task orientation. The task orientation scale used is based on the adapted Leiter-R Assessor Report (SmithDonald, Raver, \& al., 2007).This assessment measures a child's sustained attention and emotional response to frustration and boredom during the assessment. At the end of the child assessment, interviewers are asked to report on a series of specific behaviours capturing the child's ability to focus, sit still and express emotions. For example, one item asks the assessor whether the child "pays attention to instructions and demonstration." The four response options for each item are specific; for the item just described, one possible response is "child's attention frequently drifts and requires frequent prompts." Such early self-regulation skills have been linked to children's academic performance in the primary grades (McClelland, Acock, \& Morrison, 2006)

A short follow-up survey was conducted one year later, in July 2011. As part of the follow-up, we collected information on the child's primary school enrolment status. This dichotomous variable indicates whether children were enrolled in grade 1 or above at follow-up. We also collected data on children's height, weight and mid-upper arm circumference. These anthropometric measures have been used extensively in the 
health literature as proxies for child nutrition and health, and have been shown to be strongly associated with later life school and labour market outcomes (Currie, 2009; Grantham-McGregor et al., 2007; Grantham-McGregor, 2002; Hoddinott, Maluccio, Behrman, Flores, \& Martorell, 2008; Maluccio et al., 2006).

In addition to the outcome and predictor variables discussed above, we used a number of control variables in our models to attempt to correct for any imbalances between the treatment and control groups. We include the child's age in months, to adjust for the 12-month age span of children in our sample. We include a variable indicating whether the child attended any other ECE program, which will allow us to separate the associations with Amundame attendance from the associations with attendance of other programs, which would presumably be of lower quality. Socioeconomic status is a critical component of models predicting developmental and educational outcomes in developing countries, but it can be difficult to measure in settings where the majority of parents are engaged in subsistence farming or in the informal labour market. We therefore follow the approach suggested by Filmer and Pritchett (2001), and divide households into five wealth quintiles based on a principal component analysis of households' asset holdings. In addition, we include the number of siblings in the household, as larger families face additional financial pressures. As an attempt to measure another dimension of socioeconomic development, we also control for the average educational attainment of adults in the household, in years. We also control for orphanhood, which likely influences children's early development and educational experiences, in addition to the emotional effects of losing one or both parents. Evidence from teachers in Zambia's Copperbelt Province suggests that orphanhood results in greater financial and caregiving pressures on children, and is a cause of dropout (Robson \& Sylvester, 2007). With an HIV prevalence rate of over $15 \%$ among adults, and life expectancy at birth continues to be below 50 years (UNESCO, 2010; World Bank, 2012) orphanhood is unfortunately very common in the area.

\section{Analytic approach}

In order to estimate the impact of center attendance on developmental and schooling outcomes, we fit the following empirical model:

$$
y_{i}=\alpha+\beta \text { Amundame }_{i}+X_{i} \gamma+\varepsilon_{i},
$$

where $y$ is the outcome of interest for child $i$, Amundame is an indicator for whether the child ever attended the center, and $X$ is a vector of control variables as described in the previous section.

As described above, we use four measures of child development: the Peabody Picture Vocabulary Test, a letter naming task, pencil skills and task orientation. All scores for these tasks were transformed into z-scores, using standard deviations obtained from the nationally-representative Zambia Early Childhood Development Project cohort (Fink et al., 2012). The resulting standardized z-scores were used for this empirical analysis. Using z-scores allows us to compare the magnitude of 
the estimated effects of the various assessments, which are on different scales. In addition, we analyse the relationship between center attendance and weight, height, and mid-upper arm circumference. We use linear regression models to estimate the center's impact on the anthropometric and child development outcomes, and logistic maximum likelihood models for enrolment outcomes (to adjust for the binary nature of this dependent variable).

\section{Results}

\section{Characteristics of the sample}

Table 1 compares basic socio-demographic characteristics of children in the treatment and control groups. On average, children at the center were more likely to be orphans. The center is, however, less likely to be serving children of the poorest families than would be expected if spaces were allocated at random across the socioeconomic quintiles. Center children are more likely to live in slightly more educated households, and also wealthier households: on average, $20 \%$ of households in the control group were in the lowest wealth quintile, while the same was true only for $2.5 \%$ of households in the treatment group. Table 1 also illustrates the average length of exposure to the center; while children could in theory attended up to five years, the mean duration of center attendance was just under two years.

Table 1: Description of the sample

\begin{tabular}{|c|c|c|c|}
\hline Variable & $\begin{array}{c}\text { Treated } \\
(n=40)\end{array}$ & $\begin{array}{l}\text { Control } \\
(n=40)\end{array}$ & p-value \\
\hline Female child & $52.5 \%$ & $41.0 \%$ & 0.313 \\
\hline Mean household size & 6.3 & 6.5 & 0.729 \\
\hline Single or double orphan & $17.9 \%$ & $8.1 \%$ & 0.210 \\
\hline Adult education in household (years) & 8.1 & 7.0 & 0.060 \\
\hline \multicolumn{4}{|l|}{ Wealth Quintiles } \\
\hline 1 (poorest) & $2.5 \%$ & $20 \%$ & \\
\hline 2 & $15 \%$ & $12.5 \%$ & \\
\hline 3 & $40 \%$ & $25 \%$ & \\
\hline 4 & $20 \%$ & $20 \%$ & \\
\hline 5 (richest) & $22.5 \%$ & $22.5 \%$ & \\
\hline \multicolumn{4}{|l|}{ Years of Amundame attendance } \\
\hline 4 or more & $10 \%$ & & \\
\hline 3 & $10 \%$ & & \\
\hline 2 & $27.5 \%$ & & \\
\hline 1 & $52.5 \%$ & & \\
\hline 0 & $0 \%$ & & \\
\hline
\end{tabular}


Table 2 summarizes all outcome variables analysed. The first section of the table presents the developmental assessment scores collected at baseline in 2010 (prior to school enrolment). The second part of the table displays primary school enrolment statistics from the 2011 follow-up, and the third section shows anthropometric data collected during that round. Out of the 80 children originally enrolled in the study, we successfully re-assessed 70 (87.5\%) in 2011. Ten control-group children could not be located, generally because they had moved outside of the study area. Following the WHO guidelines (WHO Multicentre Growth Reference Study Group, 2006), we exclude anthropometric measures beyond 6 standard deviations from the reference medians, which results in slightly smaller sample sizes for the anthropometric outcomes.

Table 2: Average outcomes

\begin{tabular}{|l|c|c|c|}
\hline \multicolumn{1}{|c|}{ Outcome } & N & Mean & SD \\
\hline School readiness-preschool development & 80 & 21.78 & 4.13 \\
\hline Peabody Picture Vocabulary Test & 80 & 3.75 & 4.87 \\
\hline Letter naming & 80 & 2.48 & 1.57 \\
\hline Pencil skills & 80 & 3.07 & 0.74 \\
\hline Task orientation & 70 & $87.14 \%$ & \\
\hline School enrolment & 69 & 116.38 & 5.09 \\
\hline Enrolled in primary school (\%) & 65 & 21.54 & 3.01 \\
\hline Anthropometric outcomes & 69 & 16.68 & 1.39 \\
\hline Height (cm) & \multicolumn{1}{|l}{} \\
\hline Weight (kg) & \multicolumn{5}{|l}{} \\
\hline Mid-upper-arm circumference (cm) &
\end{tabular}

With respect to the school readiness tests at baseline, children answered on average 21.7 out of 30 questions correctly on the Peabody Picture Vocabulary Test, and identified 3.8 letters of the 24 tested. The average child correctly performed 2.5 out of the 4 pencil-based tasks, and got a mean item score of 3.1 on the four-point scale of the task orientation assessment. By the time of follow-up, 87 percent of children were enrolled in primary school. Since the official schooling age in Zambia is 7, and only half of study children were 7 at the time of the interview in mid-2011, these rates support other evidence that many Zambian children enrol earlier than required by law (Fink et al., 2012).

As shown in the bottom section of Table 2, the average height of children in our sample was 116 centimetres, and average weight was 21.5 kilograms. According to the internationally standardized reference table (World Health Organization, 2007), the median height in this age range ( 85 months) is 121 centimetres for girls, and 122 centimetres for boys. Children in this sample are therefore on average approximately one standard deviation below the international age-specific reference median with respect to height. The gap is slightly smaller for weight: the median reference weight is 22.6 kilograms for girls and 23.1 kilograms for boys, which means that children in 
the sample are on average about 0.5 standard deviations below the international reference median.

Table 3 shows correlations among the outcome measures analysed. The average correlation across measures is about 0.3. The highest bivariate correlations are observed for weight, height and mid-upper arm circumference, while the correlations between the school readiness measures are comparatively low.

Table 3: Correlation of outcome measures

\begin{tabular}{|c|c|c|c|c|c|c|c|c|}
\hline & ฉ & 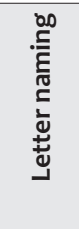 & $\begin{array}{l}\frac{n}{\overline{\bar{v}}} \\
\overline{\bar{v}} \\
\bar{v} \\
0\end{array}$ & 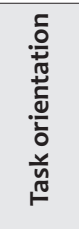 & 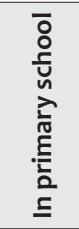 & 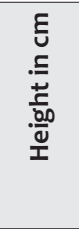 & 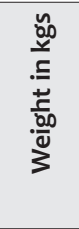 & 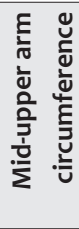 \\
\hline PPV & 1.000 & & & & & & & \\
\hline Letter naming & 0.241 & 1.000 & & & & & & \\
\hline Pencil skills & 0.345 & 0.310 & 1.000 & & & & & \\
\hline Task orientation & 0.184 & 0.393 & 0.135 & 1.000 & & & & \\
\hline In primary school & 0.233 & 0.187 & 0.205 & 0.236 & 1.000 & & & \\
\hline Height in $\mathrm{cm}$ & 0.334 & 0.024 & 0.260 & 0.206 & 0.125 & 1.000 & & \\
\hline Weight in kgs & 0.447 & 0.089 & 0.334 & 0.218 & 0.024 & 0.538 & 1.000 & \\
\hline $\begin{array}{l}\text { Mid-upper arm } \\
\text { circumference }\end{array}$ & 0.312 & 0.119 & 0.312 & 0.200 & 0.005 & 0.395 & 0.665 & 1.000 \\
\hline
\end{tabular}

\section{ECE and school-readiness-related developmental outcomes}

As discussed above, our study design limits our statistical power, and in order to observe statistically significant relationships, the associations would have to be quite large ( 0.63 standard deviations to achieve power 0.8 ). Therefore, we present our findings as exploratory and suggestive of potential effects, which may be confirmed in the future by larger national studies.

On average, the differences between the treatment and control groups appear consistent across developmental outcome measures, with treated children scoring 0.3 to 0.7 standard deviations higher than children in the control group across the four tasks (see Table 4). The relationship is strongest for task orientation, for which center attendance is associated with a higher score of 0.657 standard deviations $(p=0.01)$ on average in the model incorporating control variables. We also observe an association between center attendance and letter naming which approaches significance ( 0.481 standard deviations, $\mathrm{p}=0.06$ ). The effect sizes of PPVT, letter naming, and pencil skills are moderated by the addition of control variables (compare Models 1 and 2, 3 and 4, and 5 and 6), suggesting, unsurprisingly, that at least some portion of the differences are due to family background characteristics which differ across the two groups rather than center attendance. 
Table 4: Center attendance and pre-school development

\begin{tabular}{|l|c|c|c|c|c|c|c|c|}
\hline Outcome & \multicolumn{2}{|c|}{ PPVT } & \multicolumn{2}{c|}{ Letter naming } & \multicolumn{2}{c|}{ Pencil skills } & \multicolumn{2}{c|}{$\begin{array}{c}\text { Task } \\
\text { orientation }\end{array}$} \\
\hline & $(\mathbf{1})$ & $(2)$ & $(3)$ & $(4)$ & $(5)$ & $(6)$ & $(7)$ & $(8)$ \\
\hline Treated & 0.569 & 0.337 & 0.564 & 0.481 & 0.381 & 0.290 & 0.616 & 0.657 \\
\hline & $(0.216)$ & $(0.261)$ & $(0.216)$ & $(0.255)$ & $(0.221)$ & $(0.239)$ & $(0.214)$ & $(0.257)$ \\
\hline p-value & 0.010 & 0.200 & 0.011 & 0.064 & 0.089 & 0.229 & 0.005 & 0.012 \\
\hline Controls & No & Yes & No & Yes & No & Yes & No & Yes \\
\hline Observations & 80 & 75 & 80 & 75 & 80 & 75 & 80 & 75 \\
\hline R-squared & 0.082 & 0.139 & 0.081 & 0.235 & 0.037 & 0.309 & 0.096 & 0.193 \\
\hline
\end{tabular}

Notes: All estimates are based on linear regression models. Child development assessment outcome measures were taken at baseline, and normalized to z-scores. Columns (1), (3) and (5) show unconditional group mean comparisons. Columns (2), (4), (6) and (8) include controls for sex of child, age in months at time of baseline survey, household wealth quintile, maximum level of parental education in the household, presence of siblings, and whether the child attended any ECP. Numbers in parentheses are standard errors.

\section{ECE and physical development}

Given that Amundame chooses to invest some of its limited resources in a school feeding program, an important question is whether center attendance affected children's physical development. These results are displayed in Table 5. Overall, center attendance displayed strong positive associations with children's weight and on their mid-upper arm circumference. On average, treated children weighed close to 2 kilograms more than children in the control group at follow-up, and had an additional 1 centimetre of mid-upper arm circumference, which corresponds to 0.75 standard deviations in these two outcomes. As above, however, we must note the baseline imbalances in socioeconomic status between the treatment and control groups, which may be responsible for this observed difference at follow-up. Although these models controlled for many socioeconomic status variables, as described above, there is always the possibility that other determinants, outside the set of control variables, are driving the observed difference at follow-up.

No statistically significant relationship was identified between center attendance and height. Given that most children in the sample started attending the center only at age four or later, these results support findings elsewhere that children's height trajectories may already be established earlier in life (Howe et al., 2010), and hence respond only weakly to feeding programs in this age range (Grantham-McGregor, 2002). This finding appears consistent with the broader child development and nutrition literature, which generally views height as more of a "stock variable" 
reflecting cumulative caloric intake rather than measuring short-term nutritional inputs (Deolalikar, 1996; Sahn \& Alderman, 1997).

Table 5: Center attendance and physical development

\begin{tabular}{|l|c|c|c|c|c|c|}
\hline Outcome & \multicolumn{2}{|l|}{ Height (centimetres) } & \multicolumn{2}{c|}{ Weight (kilograms) } & \multicolumn{2}{|c|}{$\begin{array}{c}\text { Mid-upper arm } \\
\text { circumference } \\
\text { (centimetres) }\end{array}$} \\
\hline & $(\mathbf{1})$ & $(2)$ & $(3)$ & $(4)$ & $(5)$ & $(6)$ \\
\hline Treated & 1.033 & -0.188 & 1.876 & 1.818 & 0.804 & 0.993 \\
\hline & $(1.229)$ & $(1.443)$ & $(0.716)$ & $(0.920)$ & $(0.322)$ & $(0.383)$ \\
\hline p-value & 0.404 & 0.897 & 0.0110 & 0.0535 & 0.0151 & 0.0121 \\
\hline Constant & 115.9 & 95.94 & 20.65 & 20.11 & 16.27 & 13.18 \\
\hline & $(0.875)$ & $(17.63)$ & $(0.502)$ & $(11.14)$ & $(0.230)$ & $(4.676)$ \\
\hline Controls & No & Yes & No & Yes & No & Yes \\
\hline Observations & 69 & 65 & 65 & 61 & 69 & 65 \\
\hline R-squared & 0.010 & 0.040 & 0.098 & 0.119 & 0.085 & 0.258 \\
\hline
\end{tabular}

Notes: All estimates are based on linear regression models. Outcome anthropometric variables were measured at follow-up. Columns (1), (3) and (5) show unconditional group mean comparisons. Columns (2), (4), and (6) include controls for sex of child, age in months at time of follow-up survey, household wealth quintile, maximum level of parental education in the household, presence of siblings, and whether the child attended any early child care or education program. Numbers in parentheses are standard errors.

\section{Primary school enrolment}

As described in section above, more than $80 \%$ of children were enrolled in primary school when visited for the follow-up assessment in July 2011. A basic group mean comparison suggests large enrolment differences between children in our sample who attended the center and those who did not. On average, only 11 percent of treated children were not in school, while the same was true for 27 percent in the control group. The regression models shown in Table 6, which displays odds ratios for on-time primary school enrolment, further highlight these differences, although attrition from the control group at follow-up further limits the statistical power of these models. Despite the lack of statistical significance, we do observe a large association in the expected direction, even in the controlled model. An estimated odds ratio of 1.98 indicates that, conditional on all observed variables, Amundame children are almost twice as likely to be enrolled in primary school as children in the control group. 
Table 6: School enrolment outcomes

\begin{tabular}{|l|c|c|}
\hline \multicolumn{1}{|c|}{ Outcome } & \multicolumn{2}{|c|}{ Enrolled in primary school } \\
\hline & $(\mathbf{1})$ & (2) \\
\hline Treated & 2.880 & 1.980 \\
\hline & $(1.894)$ & $(1.657)$ \\
\hline p-value & 0.108 & 0.414 \\
\hline Controls & No & Yes \\
\hline Observations & 70 & 66 \\
\hline
\end{tabular}

Notes: Table displays odds ratios from a logistic regression. School enrolment was measured at follow-up. Column (1) shows the results from an unconditional group mean comparison. Column (2) includes controls for sex of child, age in months at time of follow-up survey, household wealth quintile, maximum level of parental education in the household, presence of siblings, and whether the child attended any early childhood care or education program. Numbers in parentheses are standard errors.

\section{Discussion}

The results from this research study suggest that attendance of early childhood education is associated with better physical and cognitive development and greater likelihood of on-time transition to primary school. The results presented in this paper suggest that the school readiness effects of center attendance are largest for letter naming and task orientation. Given that most non-attendees in this area are not exposed to the types of learning materials and structured activities that are offered at the Amundame center, these results appear plausible. While the center does not have highly-trained teachers, its curricular focus on letters and early literacy skills, early numeracy concepts and group play help prepare children for primary school.

Our study also suggests that center attendance makes children more likely to enrol in first grade on time. This effect would be expected, given the influence of the professional staff on families' educational decisions, the habit of attending school regularly, and the demonstrated value of school attendance. Given that attendance seems to have improved task orientation, we believe that the benefits of school attendance would be visible to parents. Beginning primary school on time is the first step in children's educational careers, and starting late can be a risk factor for dropout, as late starters will be above-age for their grade. Social and economic pressures to leave school increase with age, as alternatives to school, including paid work and marriage, become more compelling (Kingdon \& Theopold, 2006). While evidence on this issue in Zambia is limited, a number of studies in other countries have found that increasing age or age-for-grade is a risk factor for dropout (Buchmann, 2000; Ersado, 2005; Fawcett, Hartwell, \& Israel, 2010; Hunt, 2008; Lewin, 2009; Lloyd \& Mensch, 2000; Schafer, 2006).

In addition to its small sample size, the study has several important limitations. First, the children in the treatment group had, on average, short (less than 2 years) 
exposure to the Amundame Center. If we anticipate a dose-response relationship between early childhood programs and their effects, brief attendance may considerably dilute observable outcomes and we would have underestimated the true effect here. While we are not aware of any evidence from Zambia or neighbouring countries on this issue, studies in the U.S. have found dose effects for specific preschool programs: children with greater exposure to programs experienced greater growth on outcome measures (Justice, Mashburn, Pence, \& Wiggins, 2008). Second, as for any observational study, children attending the center may differ from control group children on unobservable characteristics. Although we strove to ensure comparability of the treatment and control groups by recruiting children born in the same year and living in the same area, the group comparison presented in Table 1 shows that children attending the center are on average more likely to be orphans and live with better-off households. While we control for socioeconomic and demographic characteristics in our empirical models, there might be other omitted confounders potentially biasing our results, so that the results presented cannot directly be given causal interpretation. It is worth pointing out, however, that in the context studied the direction of unobservable biases is not obvious given that the selection of children through community leaders generally focuses on identifying and supporting the most vulnerable children. Further research (and ideally also randomized control trials) will be needed to more precisely estimate the causal impact of early childhood centers like the one examined in this paper.

Last, the results presented in this paper are based on one specific center only, and raise the question regarding the degree to which similar results can be achieved elsewhere in the country. While the Amundame center is undoubtedly perceived as one of the better programs in the country, the center's reliance on the community in terms of financing, management and staff recruitment suggests that establishing similar programs in other regions should be feasible.

Overall, the findings of this study appear promising for early childhood programs Zambia as well as in sub-Saharan African countries. The Amundame model seems to be effective in supporting children's development, and it is a home-grown and community-based ECE initiative, which, after some initial support by a national foundation, has become financially independent and self-supporting. With limited governmental and private resources to support early childhood education and care, the Amundame model may offer a viable solution to meet the needs of vulnerable children for safety, health, and early academic enrichment in Zambia as well as in other countries in the region. 


\section{References}

Abbott-Shim, M., Lambert, R., \& McCarty, F. (2003). A comparison of school readiness outcomes for children randomly assigned to a Head Start program and program's waiting list. Journal of Education for Students Placed at Risk, 8(2), 191-214.

Akresh, R. (2009). Flexibility of household structure: Child fostering decisions in Burkina Faso. Journal of Human Resources, 44(4), 976-997.

Barnett, W. S. (1996). Lives in the balance: Age-27 benefit-cost analysis of the HighScope Perry Preschool Program. Ypsilanti, MI: HighScope Press.

Barnett, W. S., \& Masse, L. N. (2007). Comparative benefit-cost analysis of the Abecedarian program and its policy implications. Economics of Education Review, $26,113-125$.

Bracken, S. S., \& Fischel, J. (2007). Relationships between Social Skills, Behavioral Problems, and School Readiness for Head Start Children. NHSA Dialog, 10(2), 109- 126.

Brown, G., Scott-Little, C., Amwake, L., \& Wynn, L. (2007). A Review of Methods and Instruments Used in State and Local School Readiness Evaluations. Issues \& Answers. REL 2007-No. 004: Regional Educational Laboratory Southeast.

Buchmann, C. (2000). Family Structure, Parental Perceptions, and Child Labor in Kenya: What Factors Determine Who Is Enrolled in School? Social Forces, 78(4), 1349-1378.

Camilli, G., Vargas, S., Ryan, S., \& Barnett, W. S. (2010). Meta-Analysis of the Effects of Early Education Interventions on Cognitive and Social Development. Teachers College Record, 112(3), 579-620.

Currie, J. (2009). Healthy, Wealthy, and Wise? Socioeconomic Status, Poor Health in Childhood, and Human Capital Development. Journal of Economic Literature, 47(1), 87-122.

Deolalikar, A. B. (1996). Child nutritional status and child growth in Kenya: socioeconomic determinants. Journal of International Development, 8(3), 375-393.

Dunn, L. M., \& Dunn, L. M. (1981). Peabody Picture Vocabulary Test-Revised: American Guidance Service.

Ersado, L. (2005). Child Labor and Schooling Decisions in Urban and Rural Areas: Comparative Evidence from Nepal, Peru, and Zimbabwe. World Development, 33(3), 455-480.

Fawcett, C., Hartwell, A., \& Israel, R. (2010). Out-of-school youth in developing countries: What the data do (and do not) tell us. Washington, D.C.: USAID.

Filmer, D., \& Pritchett, L. H. (2001). Estimating Wealth Effects without Expenditure Data - or Tears: An Application to Educational Enrollments in States of India. Demography, 38(1), 115-132.

Fink, G., Matafwali, B., Moucheraud, C., \& Zuilkowski, S. S. (2012). The Zambian Early Childhood Development Project: 2010 Assessment Final Report. Cambridge, MA: Harvard University." 
Geoffroy, M.-C., Cote, S. M., Giguere, C.-E., Dionne, G., Zelazo, P. D., Tremblay, R. E., et al. (2010). Closing the Gap in Academic Readiness and Achievement: The Role of Early Childcare. Journal of Child Psychology and Psychiatry, 51(12), 1359-1367.

Gorey, K. M. (2001). Early childhood education: A meta-analytic affirmation of the shortand long-term benefits of educational opportunity. School Psychology Quarterly, 16(1), 9-30.

Grantham-McGregor, S., Cheung, Y. B., Cueto, S., Glewwe, P., Richter, L., Strupp, B., et al. (2007). Developmental Potential in the First 5 years for Children in Developing Countries. Lancet, 369, 60-70.

Grantham-McGregor, S. M. (2002). Linear growth retardation and cognition. Lancet Infectious Diseases, 359(:542).

Hanson, M. J., Miller, A. D., Diamond, K., Odom, S., Lieber, J., Butera, G., et al. (2011). Neighbourhood Community Risk Influences on Preschool Children's Development and School Readiness. Infants and Young Children, 24(1), 87-100.

Hoddinott, J., Maluccio, J., Behrman, J., Flores, R., \& Martorell, R. (2008). Effect of a nutrition intervention during early childhood on economic productivity in Guatemalan adults. Lancet, 371(9610), 411-416.

Howe, L. D., Tilling, K., Galobardes, B., Smith, G. D., Gunnell, D., \& Lawlor, D. A. (2010). Socioeconomic differences in childhood growth trajectories: at what age do height inequalities emerge? Journal of Epidemiology and Community Health, 10(1136).

Hunt, F. (2008). Dropping out from school: A cross country review of literature. Brighton, UK: University of Sussex.

Jaramillo, A., \& Tietjen, K. (2001). Early Childhood Development in Africa: Can we do more for less? Washington, D.C.: World Bank.

Jeon, H.-J., Langill, C. C., Peterson, C. A., Luze, G. J., Carta, J. J., \& Atwater, J. B. Children's Individual Experiences in Early Care and Education: Relations with Overall Classroom Quality and Children's School Readiness. Early Education and Development, 21(6), 912-939.

Justice, L. M., Mashburn, A., Pence, K. L., \& Wiggins, A. (2008). Experimental Evaluation of a Preschool Language Curriculum: Influence on Children's Expressive Language Skills. Journal of Speech, Language, and Hearing Research, 51(4), 983-1001.

Kemp, A. d., Elbers, C., \& Gunning, J. W. (2008). Primary Education in Zambia. IOB Impact Evaluation Report, 312.

Kingdon, G., \& Theopold, N. (2006). Do returns to education matter to schooling participation? Oxford, UK: University of Oxford.

Ksoll, C. (2011). Selecting Good Caretakers: The Impact of Family Networks in Tanzania on Orphans' Education Mimeo.

Lewin, K. M. (2009). Access to Education in Sub-Saharan Africa: Patterns, Problems and Possibilities. Comparative Education, 45(2), 151-174. 
Liddell, C., \& Rae, G. (2001). Predicting early grade retention: a longitudinal investigation of primary school progress in a sample of rural South African children. British Journal of Educational Psychology, 71, 413-428.

Lloyd, C. B., \& Mensch, B. S. (2000). The effects of primary school quality on school dropout among Kenyan boys and girls. Comparative Education Review, 44(2), 113.

Ludwig, J., \& Miller, D. L. (2007). Does Head Start improve children's life chances? Evidence from a regression discontinuity design. Quarterly Journal of Economics, $122,159-208$.

Macro International. (2007). Zambia: DHS, 2007 - Final Report (English). Calverton, MD.

Malmberg, L. E., Mwaura, P. A. M., \& Sylva, K. (2011). Effects of a preschool intervention on cognitive development among East-African preschool children: a flexibly timecoded growth model. Early Childhood Research Quarterly, 26(1), 124-133.

Maluccio, J. A., Hoddinott, J. F., Behrman, J. R., Martorell, R., Quisumbing, A. R., \& Stein, A. D. (2006). The Impact of Nutrition during Early Childhood on Education among Guatemalan Adults. University of Pennsylvania Population Studies Center Working Paper, 06-04.

Marcon, R. A. (1999). Positive relationships between parent school involvement and public school inner-city. School Psychology Review, 28(3), 395.

Matafwali, B. (2007). ECCD Evaluation Report. In Unicef (Eds.),

Matafwali, B., \& Munsaka, E. (2011). Programmes in Zambia: A case of four selected districts. Journal of Early Childhood Development, 5, 109-131.

McClelland, M. M., Acock, A. C., \& Morrison, F. J. (2006). The impact of kindergarten learning-related skills on academic trajectories at the end of elementary school. Early Childhood Research Quarterly, 21(4), 471-490.

Mwaura, P. A. M., Sylva, K., \& Malmberg, L. E. (2008). Evaluating the Madrasa preschool programme in East Africa: a quasi-experimental study. International Journal of Early Years Education, 16(3), 237-255.

Nganga, L. W. (2009). Early childhood education programs in Kenya: challenges and solutions. Early Years: Journal of International Research \& Development, 29(3), 227- 236.

Patrianakos-Hoobler, A. I., Msall, M. E., Marks, J. D., Dezheng, H., \& Schreiber, M. D. (2009). Risk Factors Affecting School Readiness in Premature Infants With Respiratory Distress Syndrome. Pediatrics, 124(1), 258-267.

Pence, A. R., Amponsah, M., Chalamanda, F., Habtom, A., Kameka, G., \& Nankunda, H. (2004). ECD Policy Development and Implementation in Africa. International Journal of Educational Policy, Research, and Practice: Reconceptualizing Childhood Studies, 5(3), 13-29.

Prior, M., Bavin, E., \& Ong, B. (2011). Predictors of School Readiness in Five- to Six-YearOld Children from an Australian Longitudinal Community Sample. Educational Psychology, 31(1), 3-16. 
Puma, M., Bell, S., Cook, R., Heid, C., Lopez, M., Zill, N., et al. (2005). Head Start impact study: First year findings. Washington, D.C.: US Department of Health and Human Services, Administration for Children and Families.

Rao, N. (2010). Preschool Quality and the Development of Children From Economically Disadvantaged Families in India. Part of a special issue: Accountability and Quality in Early Childhood Education: Perspectives From Asia, 21(2), 167-185.

Rao, N., Sun, J., Pearson, V., Pearson, E., Liu, H., Constas, M. A., et al. (2012). Is Something Better than Nothing? An Evaluation of Early Childhood Programs in Cambodia. Child Development, 83(3), 864-876.

Republic of Zambia Ministry of Education. (2010). Education Sector National Implementation Framework III. Lusaka: Ministry of Education.

Reynolds, A. J. (2000). Success in early intervention: The Chicago Child-Parent Centers. Lincoln, NE: University of Nebraska Press.

Robson, S., \& Sylvester, K. B. (2007). Orphaned and Vulnerable Children in Zambia: The Impact of the HIV/AIDS Epidemic on Basic Education for Children at Risk. Educational Research, 49(3), 259-272.

Romano, E., Babchishin, L., Pagani, L. S., \& Kohen, D. School Readiness and Later Achievement: Replication and Extension Using a Nationwide Canadian Survey. Developmental Psychology, 46(5), 995-1007.

Sahn, D. E., \& Alderman, H. (1997). On the determinants of nutrition in Mozambique: The importance of age-specific effects. World Development, 25(4).

Schafer, M. J. (2006). Household Change and Rural School Enrollment in Malawi and Kenya. The Sociological Quarterly, 47(4), 665-691.

Schweinhart, L. J., Montie, J., Xiang, Z., Barnett, W. S., Belfield, C. R., \& Nores, M. (2005). Lifetime effects: The HighScope Perry Preschool study through age 40. Ypsilanti, MI: HighScope Press.

Smith-Donald, C., Raver, C., \& al., e. (2007). Preliminary construct and concurrent validity of the Preschool Self-regulation Assessment (PSRA) for field-based research. Early Childhood Research Quarterly, 22(2), 173-187.

Taiwo, A. A., \& Tyolo, J. B. (2002). The effect of preschool education on academic performance in primary school: A case study of grade one pupils in Botswana. International Journal of Educational Development, 22, 169-180.

Thomas, C. M., \& Thomas, M. A. M. (2009). Early Childhood Care and Education in Zambia: An Integral Part of Educational Provision? Current Issues in Comparative Education, 11, 6-14.

UNESCO. (2010). EFA Global Monitoring Report 2010: Reaching the Marginalized. Paris: UNESCO.

UNESCO. (2011). Education for All Global Monitoring Report: The Hidden Crisis: Armed Conflict and Education. Paris: UNESCO.

Unicef. (2012). Unicef Country Statistics (Publication. Retrieved March 2012: http:// www.unicef.org/infobycountry/brazil_statistics.html 
WHO Multicentre Growth Reference Study Group. (2006). WHO Child Growth Standards: Length/height-for-age, weight-for-age, weight-for-length, weight-forheight and body mass index-for-age: Methods and development. Geneva: World Health Organization.

World Bank. (2012). World Development Indicators Online database.

World Health Organization. (2007). WHO Reference 2007 (Publication., from World Health Organization: http://www.who.int/growthref/en/

Young, M. E. (1996). Early Child Development: Investing in the Future. Washington, D.C.: World Bank. 